\section{Estudo \\ CoDebate}

em Crestão

Planejamento
Revista Estudo \& Debate, Lajeado, v. 27, n. 4, 2020. ISSN 1983-036X

DOI: http://dx.doi.org/10.22410/issn.1983-036X.v27i4a2020.2493

\title{
QUALIDADE DE VIDA DE PRODUTORES RURAIS QUE REALIZAM GINÁSTICA LABORAL
}

\author{
Claudionor Nunes Cavalheiro ${ }^{1}$, Claudete Rempel ${ }^{2}$, Ana Paula de Borba Morás ${ }^{3}$
}

\begin{abstract}
Resumo: Os pequenos produtores rurais exercem inúmeras atividades voltadas à agricultura e pecuária em suas propriedades sem ter uma carga horária definida, baseando-se de acordo com a necessidade da realizaçáo das tarefas. A ginástica laboral tem sido utilizada em diversas intervenções visando à melhora da qualidade de vida dos trabalhadores de setores urbanos, contudo, no setor rural, esta prática é ainda incipiente. Assim, objetiva-se avaliar a mudança na qualidade de vida de produtores de leite participantes do programa de atividades de ginástica laboral da Comunidade de São Justino em Juína/MT. Foi realizado uma análise do perfil socioeconômico dos ordenadores da comunidade e traçada a qualidade de vida dos mesmos antes e após intervenção com ginástica laboral. Para avaliaçáo física dos ordenadores foi realizado o teste da quantidade de dor, por meio da Escala Visual Analógica da Dor, flexibilidade (Banco de Wells) e qualidade de vida (WHOQOL-bref). As médias de qualidade de vida dos participantes da pesquisa melhoraram significativamente após a intervenção e houve melhora na flexibilidade e diminuiçáo da incidência de dor nos segmentos corporais citados. A ginástica laboral no meio rural também pode ser utilizada para melhoria da qualidade de vida dos produtores bem como melhora física.
\end{abstract}

Palavras-chave: Comunidade Rural; Desempenho Laboral; Qualidade de vida; Exercício físico

\section{QUALITY OF LIFE OF RURAL PRODUCERS WHO PERFORM LABOR GYMNASTICS}

\begin{abstract}
The small rural producers carry out numerous activities aimed at agriculture and livestock on their properties without having a defined workload, based on the need to carry out the tasks. Labor gymnastics has been used in several interventions aimed at improving the quality of life of workers in urban sectors, however, in the rural sector, this practice is still incipient. So, the objective is to evaluate the change in the quality of life of milk producers participating in the work program of labor gymnastics of the Community of São Justino in
\end{abstract}

1 Educador Físico. Mestre em Ambiente e Desenvolvimento pela Univates, Professor do Instituto Federal Mato Grosso - Campus Primavera do Leste.

2 Bióloga. Doutora em Ecologia pela UFRGS. Professora do Centro de Ciências Médicas e dos Programas de Pós-Graduação em Ambiente e Desenvolvimento e em Sistemas Ambientais Sustentáveis da Universidade do Vale do Taquari - Univates

3 Acadêmica de Ciências Biológicas, Bacharelado e Bolsista de Iniciação Científica da Universidade do Vale do Taquari - Univates (Bolsa FAPERGS) 
Juína / MT. An analysis was made of the socioeconomic profile of the community computers and their quality of life was traced before and after workout. For the physical evaluation of the computers, the pain quantity test was performed through the Visual Analogue Pain Scale, flexibility (Wells Bank) and quality of life (WHOQOLbref). The quality of life averages of the research participants improved significantly after the intervention and there was improvement in flexibility and decrease of the incidence of pain in the cited body segments. Work gymnastics in rural areas can also be used to improve the quality of life of the producers as well as physical improvement.

Keywords: Rural Population, Work Performance, Quality of Life, Physical exercise

\section{Introduçáo e Referencial Teórico}

No Mato Grosso, aproximadamente $86 \%$ dos produtores de leite geram até 100 litros/dia e realizam ordenha manual, mas considerando até 50 litros/dia, a porcentagem sobe para 95\% (FAMATO, 2011). Esses valores são somente dos muitos produtores da região que produzem quantidades inferiores de leite devido à ausência de tecnologias para incrementar suas produçóes, como uma ordenhadeira mecânica. Este equipamento, conforme resultados de estudo realizado na mesorregiāo do sudeste do Rio Grande do Sul (PICOLI et al., 2014), ampliam significativamente a produção de leite, aproximadamente três vezes mais que de ordenha manual.

Os pequenos produtores rurais exercem inúmeras atividades voltadas à agricultura $\mathrm{e}$ pecuária em suas propriedades sem ter uma carga horária definida, baseando-se de acordo com a necessidade da realização das tarefas. Mesmo que a família auxilie, a sobrecarga ao produtor responsável é muito comum no âmbito rural, tanto física quanto psicológica e emocionalmente. A má postura é uma das principais causas de desconforto no trabalho (OLIVEIRA; MORO; ULBRICHT, 2017), principalmente para produtores que realizam ordenhas manuais, em que a execução ocorre de forma repetitiva.

Para a realização das tarefas há um procedimento a ser seguido (EMBRAPA, 2018) com horários desvantajosos que desgastam a saúde física e mental dos envolvidos. Pelo motivo de se dedicarem totalmente à atividade agropecuária, o tempo para o lazer, prática de atividades físicas e desenvolvimento de habilidades é reduzido, e as consequências surgem a longo prazo, refletindo na vitalidade dos produtores. Um exemplo é de um estudo em Juína/ MT, onde foram calculadas 14,7 horas diárias, aproximadamente, destinadas às atividades da propriedade (CAVALHEIRO et al., 2014). Essa baixa disponibilidade dos produtores de leite pode afetar a questão social, não tendo tanto tempo para usufruir com visitas a parentes, amigos e vizinhos, restringindo o contato para quem for no estabelecimento, como leiteiros e técnicos de qualidade das empresas integradoras, técnicos de órgãos governamentais, e outros profissionais relacionados, ou para quando os próprios produtores necessitam ir resolver questôes familiares, da produção e afins.

A prática de atividades físicas regulares reforça a estrutura corporal que é de grande importância para manter a energia e estímulo nas atividades gerais. Considerando que produtores não possuam tempo suficiente para prática de exercícios, há a opção da ginástica laboral, que consiste em uma pausa de curta duração no decorrer do dia de trabalho para alongamentos e relaxamento físico e mental, tendo o propósito de melhorar o bem-estar e a produtividade do trabalhador (SANTOS et al., 2007). Para tanto, o objetivo deste estudo 
foi de verificar o impacto da ginástica laboral na qualidade de vida de produtores de leite da Comunidade de São Justino em Juína/MT.

\section{Métodos}

Quanto à natureza, a pesquisa caracteriza se como aplicada. Quanto ao modo de abordagem do problema é qualiquantitativa. Quanto ao aos objetivos, a pesquisa é explicativa, descritiva e trata-se de um estudo de caso. Para tanto, utiliza o método indutivo, que obtém conclusóes gerais a partir de premissas individuais.

O estudo segue as diretrizes da Resolução 466/12, do Ministério da Saúde, que regulamenta todas as pesquisas envolvendo seres humanos no Brasil. Foi submetido e aprovado pelo Comitê de Ética em Pesquisa (Coep) da Universidade do Vale do Taquari Univates, com parecer no 703.687.

A pesquisa foi realizada com cinco ordenhadores das oito propriedades produtoras de leite que realizam a ordenha de forma manual na Comunidade São Justino em Juína/MT entre os meses de setembro de 2013 e março de 2014. Parte da pesquisa foi desenvolvida na sede da Comunidade dos Produtores e parte nas propriedades rurais dos ordenhadores. A seleçáo dos sujeitos da pesquisa ocorreu por meio de convite formal feito pessoalmente pelo Presidente da Comunidade juntamente com os pesquisadores, dando liberdade aos ordenhadores de aceitarem ou não participar na pesquisa.

Foram utilizadas como técnicas de pesquisa a aplicação do instrumento para analisar o perfil socioeconômico dos ordenhadores, o instrumento WHOQOL bref para verificar a qualidade de vida dos participantes, o Banco de Wells para verificar a flexibilidade e escala visual analógica (para a percepção de dor, todos com intuito de coletar dados para a estruturação dos exercícios de ginástica laboral que foram utilizados na intervenção, que teve duração de seis meses. As falas e percepções apresentadas pelos ordenhadores foram gravadas e, a seguir, transcritas para a organização e análise dos dados, com base no método de análise de conteúdo (BARDIN, 2012).

O instrumento para análise das atividades de trabalhos dos ordenhadores foi aplicado no início da pesquisa e o instrumento WHOQOL bref foi aplicado no início da pesquisa e ao final da intervenção da ginástica laboral. Os demais testes foram realizados ao início da pesquisa e a cada dois meses de realização da intervenção, culminando com um teste final ao término do programa de ginástica laboral. Desta forma, os testes realizados antes da intervenção tiveram a intenção de estruturar o programa executado pelos ordenhadores, e os testes realizados durante a intervenção serviram para observar os resultados obtidos com a prática sistemática da ginástica laboral. Sempre que o indivíduo a ser analisado era do sexo feminino houve a presença de uma mulher durante a coleta de dados com o intuito de evitar constrangimentos ao sujeito da pesquisa.

No primeiro momento, em reunião com todos os participantes na sede da Comunidade São Justino em Juína/MT, os ordenhadores receberam as orientações do pesquisador sobre os objetivos do estudo e assinaram o Termo de Consentimento Livre Esclarecido TCLE.

Para identificar os indivíduos participantes da pesquisa, foi aplicado o Instrumento para análise das atividades de trabalho dos ordenadores e o Instrumento para análise das 
atividades de trabalho dos ordenhadores, no qual foram coletadas informaçóes relativas à sua família e trabalho com a coletadas informaçóes relativas à sua família e trabalho com a ordenha e afins. O instrumento foi aplicado individualmente na propriedade do ordenhador, sendo este o local onde o produtor se sente mais à vontade para respondê-lo. Com este instrumento, foi averiguado o peso e altura dos ordenhadores com o intuito de obterordenhadores com o intuito de obter-se o Índice de Massa Corporal (IMC), que é obtido a partir da divisão da massa corporal em quilogramas, pela estatura em metro, elevada ao quadrado $\left(\mathrm{kg} / \mathrm{m}^{2}\right)$.

A aplicação do instrumento WHOQOL-bref foi feita de forma individualizada na propriedade de cada ordenhador. O WHOQOL-bref é um é um instrumento autoaplicável e investiga a percepção do indivíduo a respeito da sua qualidade de vida, ou seja, a percepção do indivíduo de sua posição na vida no contexto da cultura e sistema de valores nos quais ele vive e em relação aos seus objetivos, expectativas, padrões e preocupações (THE WHOQOL GROUP apud FLECK, 1995. Este instrumento compreende 26 questóes, denominadas facetas, por meio das quais são investigados quatro domínios: físico, psicológico, ambiental e das relações sociais. Ele é a versão abreviada do instrumento WHOQOL-100, composto por cem questóes, cuja construção contou com a participação de especialistas de diversos países, para que se obtivesse um enfoque transcultural. A versão em português dos instrumentos WHOQOL foi desenvolvida no Departamento de Psiquiatria e Medicina Legal para o Brasil, no Departamento de Psiquiatria e Medicina Legal da Universidade Federal do Rio Grande do Sul em 1998, sob a coordenação do Dr. sob a coordenação do Dr. Marcelo Pio de Almeida Fleck. Marcelo Pio de Almeida Fleck.

No referido instrumento é solicitado que o indivíduo pesquisado faça uma reflexão sobre as duas últimas semanas de sua vida e avalie como se sente em relação à sua qualidade de vida, tendo em mente seus valores, aspiraçóes, prazeres e preocupaçóes, devendo assinalar somente uma das cinco alternativas apresentadas para cada uma das questóes.

O domínio físico no instrumento WHOQOL-bref corresponde às questôes 3, 4, $10,15,16,17$ e 18, com sete itens: dor e desconforto; energia e fadiga; sono e repouso; mobilidade; atividades da vida cotidiana; dependência de medicação ou tratamento e capacidade de trabalho.

O domínio psicológico é formado pelas questóes 5, 6, 7, 11, 19 e 26, fazendo parte desse domínio os itens de sentimentos positivos, pensar, aprender, memória e concentração; imagem corporal e aparência, sentimentos negativos e crenças pessoais.

As relaçôes sociais representam três itens: relações pessoais, suporte social e atividade sexual nas questóes 20, 21 e 22 e o quarto domínio refere-se ao meio ambiente que é formado pelos itens de segurança física e proteção; ambiente no lar; recursos financeiros; cuidados de saúde e disponibilidade sociais e qualidade; oportunidade de conseguir novas informaçóes e habilidades, participação e oportunidade de recreação e lazer; ambiente físico (poluição, ruído, trânsito e clima) e transporte, sendo esses itens correspondidos pelas questóes $8,9,12,13,14,23,24$ e 25 .

As questóes do instrumento WHOQOL-bref possuem quatro tipos de escalas de respostas (intensidade, capacidade, frequência e avaliação), cada uma com cinco níveis. 
A escala de intensidade varia de "nada" ao "extremamente" (questôes 3 a 9). A escala de capacidade varia de "nada" ao "completamente" (questóes 10 a 14). A escala de avaliação varia de "muito insatisfeito" a "muito satisfeito" (questóes 16 a 25 e questão 2) e "muito ruim" a "muito bom" (questóes 1 e 15). A escala de frequência varia de "nunca" a "sempre" (questão 26). Todas essas palavras são denominadas âncoras, e cada uma delas possui uma pontuação de 1 a 5, sendo que os escores questóes 3, 4 e 26 são invertidos da seguinte forma: se a resposta for 1 , a pontuação será 5 ; se 2 , será 4 e, assim, sucessivamente.

A determinação dos escores dos domínios do WHOQOl-bref é realizada da seguinte forma: na primeira etapa, inicialmente, deve-se somar todos os itens incluídos dentro de um domínio. Após, divide-se pela média de questóes respondidas e, posteriormente, multiplica-se por quatro. $\mathrm{Na}$ segunda etapa, diminui-se de cada domínio o valor de quatro e multiplica-se por 6,25 (ou 100/16). Desse modo, o resultado final de cada domínio vai variar de 0 a 100. Para melhor compreensão das pontuaçóes, a escala foi dividida em cinco categorias, seguindo a proposta de Padrão e Sens (2009), sendo: Muito Ruim (0-20), Ruim (21-40), Nem ruim nem boa (41-60), Boa (61-80), Muito boa (81-100).

A flexibilidade foi avaliada no início da pesquisa e a cada dois meses, durante a intervençâo, pelo teste de Wells e Dillon (1952), também denominado teste de sentar e alcançar, que é uma medida linear e quantitativa. Conforme descrevem Lima et al. (2010), o teste avalia a flexibilidade envolvendo a musculatura isquiotibial e a região lombar. Para a realização do teste, que foi de forma individualizada na propriedade do ordenhador, este estava com uma roupa que não limitasse seus movimentos, sentado sobre um colchonete com os joelhos estendidos, membros inferiores levemente afastados com os pés apoiados na estendidos e ombros fletidos. Em seguida realizava a flexão de tronco, avançando lentamente para frente com ambas as mãos (paralelas), tão longe quanto possível, mantendo essa posição momentaneamente. O ordenhador foi orientado a respirar normalmente durante o teste e a não prender a respiração. $\mathrm{O}$ resultado foi o ponto mais distante, $\mathrm{em} \mathrm{cm}$, atingido com as pontas dos dedos. O protocolo de teste foi baseado nas recomendaçóes de Achour Júnior (1999) para os procedimentos usuais do teste de sentar e alcançar, sendo a medida tomada três vezes e considerada apenas a maior delas. Foi solicitado ao ordenhador que fizesse o teste com roupas apropriadas para a atividade física.

A escala visual analógica para a percepção de dor é um instrumento unidimensional para a avaliação da intensidade da dor. Esta foi mensurada no início da pesquisa e a cada dois meses, durante a intervenção. Scopel, Alencar e Cruz (2007) descrevem que o teste consiste na medida de uma linha horizontal de $10 \mathrm{~cm}$, com âncoras em ambas as extremidades. Numa delas é marcada "sem dor" e na outra extremidade é indicada "pior dor possível". A magnitude da dor é indicada marcando a linha, e uma régua é utilizada para quantificar a mensuração numa escala de 0 a $10 \mathrm{~cm}$.

De acordo com Huskisson apud Sousa e Silva (2005), este instrumento tem sido considerado sensível, simples, reproduzível e universal, ou seja, pode ser compreendido em distintas situaçóes onde há diferenças culturais ou de linguagem do avaliador, clínico ou examinador.

De posse dos dados coletados, esses foram tabulados e analisados para ter-se um parâmetro da qualidade de vida dos ordenhadores, sua flexibilidade e em quais segmentos 
corporais os mesmos sentiam dores, com o intuito de estruturar um planejamento individualizado de ginástica laboral que atendesse às demandas dos mesmos. A intervenção proposta foi de seis meses de ginástica laboral, realizada todos os dias da semanada semana, sendo que no primeiro mês os ordenhadores tiveram o acompanhamento de um os pesquisadores nos dias na execução dos exercícios.

Excepcionalmente, no primeiro mês, a prática da ginástica laboral foi feita em dois momentos distintos: a primeira, no período matinal antes da atividade laboral, onde o ordenhador acompanhava o programa de exercício e os realizava sozinho, e a e a segunda, no período vespertino com acompanhamento de um dos pesquisadores para sanar dúvidas advindas da execução e correção de possíveis erros de execução. $\mathrm{O}$ fato do pesquisador não acompanhar os exercícios de alongamento feitos pelos ordenhadores no período matutino deu-se por solicitação dos mesmos, tendo em vista que a presença de estranhos na propriedade poderia afetar o conforto dos animais, deixando-os estressados e afetando assim a produção leiteira. Após passado o primeiro mês, os cinco meses restantes tiveram o acompanhamento diário do pesquisador e de um bolsista, sempre em dias alternados entre ambos, sendo a visita do pesquisador para supervisionar a execução correta dos exercícios de alongamento e sanar possíveis dúvidas advindas da pesquisa, e por parte da bolsista a execução diária dos exercícios. Os alongamentos foram realizados todos os dias da semana, sendo executados três séries de 10 segundos cada, intensidade moderada, com intervalo de cinco segundos entre uma série e outra, totalizando média de 10 a 15 minutos por sessão de ginástica laboral.

Decidiu-se por realizar uma intervenção preventiva utilizando a ginástica laboral de aquecimento ou preparatória, por entender que o trabalho do ordenhador é sempre feito nas primeiras horas do dia, quase sempre antes do alvorecer. A partir desta observação, o "corpo" vai para o labor sem a devida preparação para a atividade física, exigindo assim dos músculos, uma carga por vezes maior do que ele está preparado para suportar não estando em uma temperatura ideal para o exercício físico. Para Lima (2003), a ginástica laboral é uma adequação da atividade física ao ambiente de trabalho e visa promover adaptaçóes fisiológicas, físicas e psíquicas por meio de exercícios. Segundo Maciel et al. (2006) a ginástica laboral basicamente tem como objetivos promover saúde, melhorar as condiçóes de trabalho e preparar os trabalhadores para o despertar para a prática de atividades dentro e fora do trabalho.

Foi recomendado aos ordenhadores que fizessem os alongamentos antes de irem para a lida com o gado leiteiro, preferencialmente antes mesmo de saírem de suas casas rumo ao piquete para buscarem as vacas, ou mesmo para o curral para a ordenha propriamente dita.

Por acreditar que o corpo não é composto de partes unificadas trabalhou-se com alongamentos para todo o corpo, e não apenas a musculatura mais exigida na atividade de trabalho, distribuindo a sessão de ginástica laboral com exercícios específicos para cada segmento corporal, pois embora os membros superiores sejam os mais utilizados na ordenha, as regióes cervical e lombar são bastante exigidas, principalmente por questóes posturais ao realizar a atividade de ordenha.

Da mesma forma, os membros inferiores, quando por tempo prolongado em uma mesma posição, têm suas funções biomecânicas prejudicadas. Os alongamentos seguiram 
sempre a ordem de segmentos corporais, começando pelo: pescoço, parte superior das costas, ombros, braços, pulsos, quadril, parte anterior das pernas, parte posterior das pernas e finalizando com a parte inferior das costas.

Para avaliar-se a relação entre as variáveis, foi realizado o teste t de Student para comparação do antes e após a intervenção. Os dados foram analisados no software Bioestat $5.0^{\circ}$ e consideradas significativas as diferenças $\mathrm{p} \leq 0,05$ e os dados de média e desvio padráo são apresentados na forma de média (desvio padrão).

\section{Resultados e Discussáo}

Do perfil socioeconômico dos ordenadores, $80 \%$ são do sexo masculino com idades aproximadas a 46 anos, e $20 \%$ do sexo feminino, de idade média 52 anos. Os ordenhadores são naturais das regiôes Sudeste e Sul do Brasil, locais de destaque na produçâo de leite. Em relação à experiência, constatou-se que todos possuem alto nível, podendo-se notar que esta atividade, pelas idades médias, é voltada para adultos. Em relação ao grau de escolaridade, a maioria (80\%) possui até o ensino fundamental, sendo somente $20 \%$ o ensino médio incompleto, representando este último o produtor que possui a maior produçâo de leite.

Constatou-se que na Comunidade Sáo Justino há uma multifuncionalidade do produtor de leite, pois ele complementa sua renda familiar com lavouras de café, olericultura, produção para subsistência e venda, além de comércio de derivados do leite, criaçáo de pequenos animais, e até mesmo realizando serviços fora do âmbito rural, em laticínios. Somente $20 \%$ têm a atividade leiteira como única fonte de renda. Os produtores trabalham em sua própria área de terra, que possui em média 38,36 hectares, sendo boa parte ocupada para lavouras e pouca Área de Preservação Permanente (APP) com cobertura vegetal.

Outra constatação obtida analisando o perfil socioeconômico dos entrevistados está relacionada à ordenha. Ela é manual em toda a Comunidade Sáo Justino, em que os produtores procedem somente uma vez por dia, pois justificam a incapacidade de realizar duas vezes essa tarefa sozinhos, ordenhando-se em média nove vacas por dia (CAVALHEIRO et al., 2014), obtendo-se um valor médio de 37,9 litros/dia (FAMATO, 2006; CAVALHEIRO et al., 2014). Visto que a ordenha é manual e considerando o valor médio de vacas ordenhadas, o produtor necessita 1,8 horas/dia para realizar a atividade, ocupando-se do restante do tempo para outras tarefas cotidianas.

Em relação ao questionário WHOQOL-bref de qualidade de vida dos produtores, a análise do antes e do depois foi feita, destacando alguns pontos. O escore médio de qualidade de vida subiu de 70,3 para 79,4, um aumento de aproximadamente $13 \%$ com a realização da ginástica laboral. Conforme a Figura 1, todos os domínios apresentaram melhorias em seus escores, em que o DF obteve o maior aumento nos escores, sendo a diferença significativa ( $\mathrm{p}<0,02)$, de $29,9 \%$, seguido do DA $(12,5 \%)$, DS $(8,4 \%)$ e DP $(2,2 \%)$. 
Figura 1: Gráfico de escores médios iniciais e pós-intervenção da qualidade de vida de cada domínio analisado, dos ordenhadores da Comunidade São Justino - Juína/MT

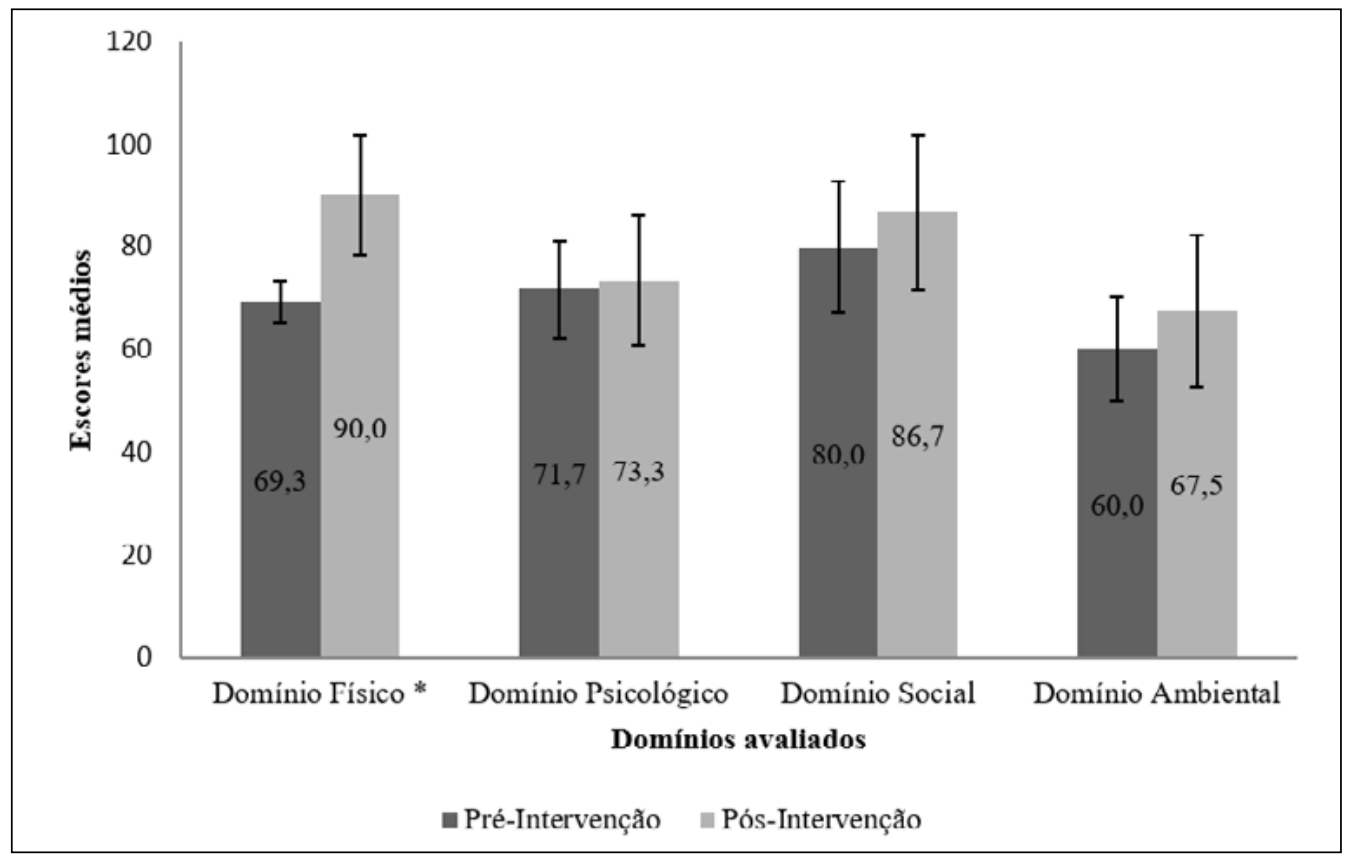

Fonte: Dados da pesquisa (2017).

O alto escore para o domínio social desse estudo se deve à frequência do contato com outras pessoas em reuniōes da comunidade, da associação de agricultores, e pelas atitudes solidárias entre os produtores da regiáo, além do hábito de encontros semanais na igreja, com o costume de realizar mutiróes em prol dos moradores que estejam apresentando qualquer tipo de dificuldade. Para o domínio psicológico foram consideradas a aceitação em relação à sua aparência física, sentido da vida, presença constante de sentimentos negativos, como desespero e ansiedade, e satisfação do produtor consigo mesmo.

Já do domínio ambiental, em que fora registrada a média mais baixa, considerouse a satisfação dos entrevistados em relação ao quanto se sentem seguros, o quão bom é o ambiente que vivem, sobre poluição no geral, inclusive sonora, em relação às condiçóes financeiras que apresentam e ao tempo disponível para lazer, sendo este último o motivo principal para o baixo escore. Do domínio físico, considerou-se a percepção dos entrevistados na constância da dor, necessidade de tratamento para tal, quantidade de energia para as tarefas diárias, capacidade de locomoção e realizar o trabalho. Também foi considerada para a análise o cálculo do IMC desses produtores, em que a média obtida foi de 27,4, caracterizando os entrevistados como pessoas com sobrepeso (ABESO, 2016).

$\mathrm{Da}$ análise da flexibilidade dos produtores (Figura 2), que se obtiveram os resultados com o teste de sentar e alcançar, além de utilizar o Banco de Wells para traduzir a informação, registrou-se que $60 \%$ dos produtores estavam com a flexibilidade bem baixa, longe do que se esperava para um grupo de pessoas com essas características e faixa etária, resultando 
na informação "necessita melhorar". Do restante de entrevistados, 20\% estavam com seu nível considerado "bom", e 20\% “excelente". Após a intervenção da ginástica laboral, ao final do estudo, os resultados mudaram significativamente. Os índices de flexibilidade subiram para $80 \%$ dos produtores, com uma elevação de $5 \%$ para o ordenhador 2, 38\% para o ordenhador 3, 31\% para o 4 e $86 \%$ para o 5 . O ordenhador 1 foi o único que teve decréscimo em sua flexibilidade (redução de 21\%), mas nada interferiu em seu nível, que ainda é considerado excelente.

Figura 2: Gráfico da evolução da flexibilidade dos produtores de leite da Comunidade São Justino em Juína/MT com a aplicação da ginástica laboral

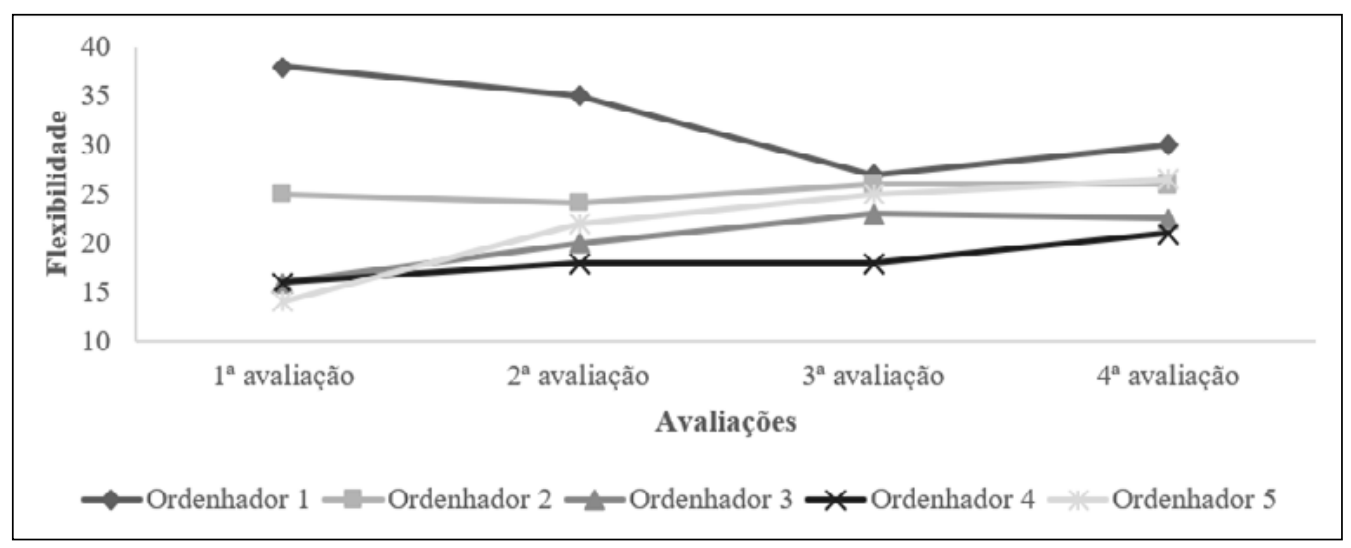

Fonte: Dados da pesquisa (2017).

A EVA, teste utilizado para os produtores analisarem a presença de dor nas diferentes partes do corpo, mostrou que $100 \%$ dos participantes da pesquisa sentiam dores, sendo que o maior índice foi na região inferior das costas, ou lombar, seguido dos pulsos/mãos (Figura 3) (MARTINS, 2001). Ao término da pesquisa, esta mesma análise foi reaplicada e somente $40 \%$ dos produtores relataram sentir dor ou desconforto ao realizar as tarefas diárias, porém, somente na região do ombro e parte inferior das costas (Figura 4) (MARTINS, 2001). Todos os ordenhadores constataram que ao longo da prática dos alongamentos, as dores foram diminuindo a ponto de não interferirem mais nas atividades leiteiras, confirmando o resultado obtido sobre incidência de dor. 
Figura 3: Esquema de incidência de dor nas regióes corporais dos ordenhadores da Comunidade São Justino em Juína/MT antes da realização de ginástica laboral

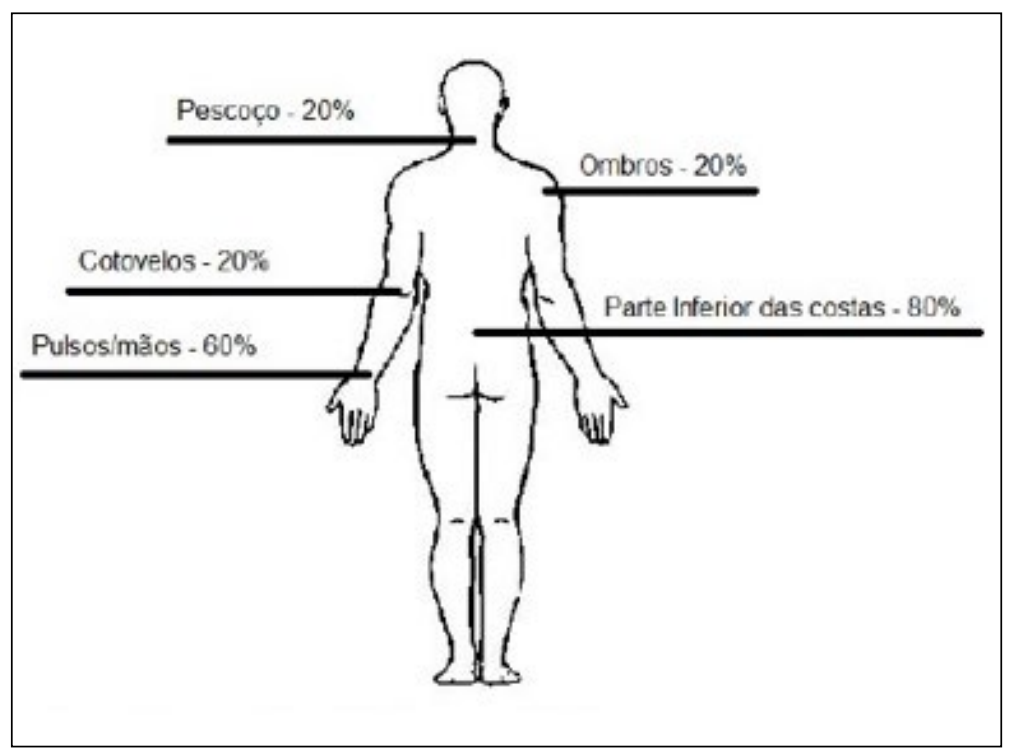

Fonte: Dados da pesquisa (2017).

Figura 4: Esquema de incidência de dor nas regióes corporais dos ordenhadores da Comunidade São Justino em Juína/MT ao final do estudo, pós-intervenção

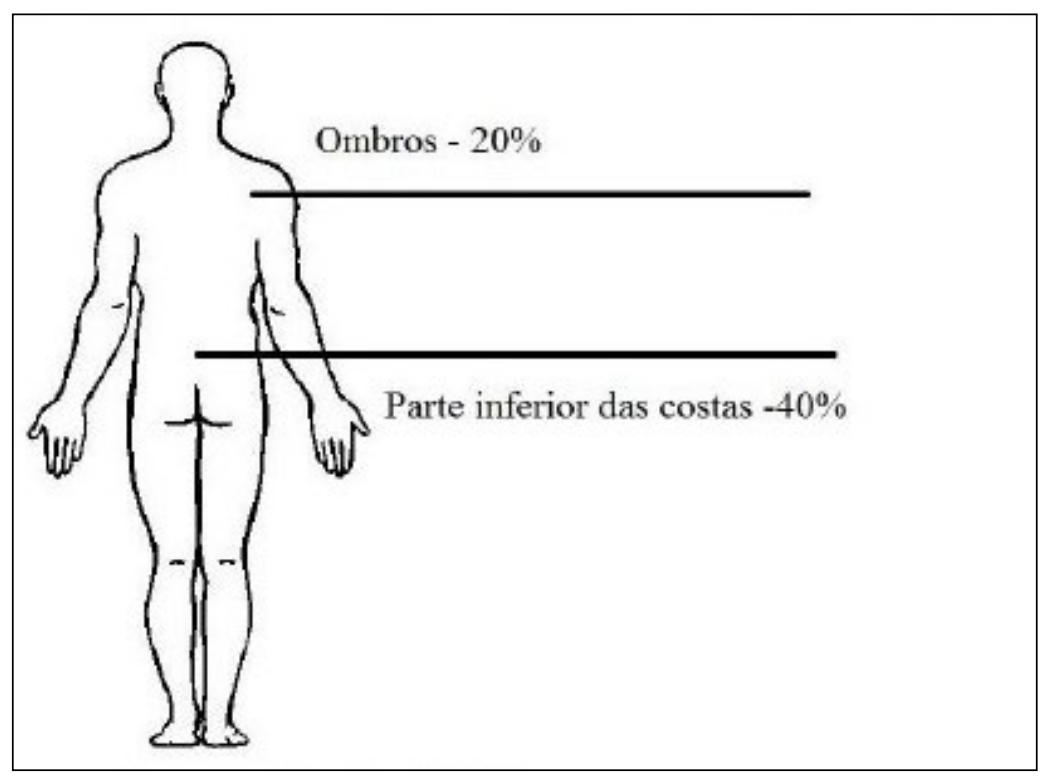

Fonte: Dados da pesquisa (2017). 
Foi diagnosticado no relatório de pesquisa da cadeia produtiva do leite que, no estado Mato Grosso, a idade média dos produtores entrevistados é 50 anos (FAMATO, 2011), resultado este de acordo com os obtidos neste estudo. Apesar do número de entrevistados ser baixo, é possível verificar uma predominância de homens no comando das atividades leiteiras, porém, a porcentagem de mulheres na direção das tarefas é maior comparando com demais pesquisas, como no Distrito Federal, que a porcentagem foi de 11,6\% (BRIZOLA; GUIMARÃES, 2014), ou em Minas Gerais, sendo somente 5\%.

No mesmo relatório foi correlacionada a escolaridade com o estrato de produção de leite e foi constatada positiva a associação, ou seja, quanto menor o grau de escolaridade, menor é a produção de leite (FAMATO, 2011). Na análise do perfil socioeconômico de produtores de leite em outras regióes do país (BRIZOLA; GUIMARÁES, 2014; MOURA; REMPEL; KOETZ, 2019), eles apresentaram perfil semelhante, com idade média acima de 40 anos e a maioria de baixa escolaridade, o que dificulta a aceitação em adquirir novas tecnologias para melhorar a qualidade e quantidade da produção. Ainda, autores comentam que produtores com pouca instrução não descartam o leite de vacas em tratamento de doenças, como a mastite, evitam o uso de equipamentos de proteção individual (EPIs), e perdem a possibilidade de receber bonificação por qualidade do leite (BORSANELLI et al., 2014).

Em estudo com uma vasta gama de entrevistados em Santa Catarina (WINCK; THALER NETO, 2014), seja de ordenha manual como mecânica, nenhum tinha como única fonte de renda o leite, porém, foi destacado que $88 \%$ dos entrevistados consideravam a atividade leiteira como uma das duas principais tarefas lucrativas. Com essa constatação, juntamente com o resultado dessa pesquisa, é possível observar que a renda com o leite é insuficiente, obrigando os produtores a se ocupar com atividades secundárias, gerando uma maior sobrecarga devido às diversas tarefas. Ao ser analisado o perfil socioeconômico de comunidades rurais de Juína formadas por agricultura familiar (DAUGEARD, 2017), constatou-se que a resiliência voltada à produção leiteira é incapacitada devido a fragilidades do setor primário. Ou seja, quando imprevistos aparecem e interferem no lucro do produtor dedicado somente à produção de leite, este não consegue retornar à situação e acaba prejudicado, situação esta que o incentiva a incrementar a renda ou substituí-la por outra mais garantida.

A área média obtida das propriedades participantes da pesquisa está dentro do que se considera agricultura familiar conforme legislação federal no 11.326/2006 (BRASIL, 2006), em que um dos requisitos é ter a área até 4 módulos fiscais, o que compreende, em Juína, até 400 hectares (INCRA, 2013). No norte do estado de Minas Gerais um estudo semelhante foi aplicado (MENEZES et al., 2014), registrando-se uma predominância de propriedades de leite baixo nível tecnológico, ou seja, com ordenha manual, e de área compreendendo 1 a 50 hectares, semelhante à média obtida pelo autor no estudo.

Em relação ao número de vacas ordenhadas por dia, foi constatada quantidade próxima no estudo em Santa Catarina (WINCK; THALER NETO, 2014) para pequenas propriedades de leite, em que se registraram 9,4 a 7,9 vacas em lactação para a ordenha diária e uma média de 42 litros/dia, confirmando a semelhança de produção animal/dia. Isso demonstra que a ordenha manual pode limitar o produtor, dificultando a possibilidade 
de aumentar o rebanho devido à baixa capacidade de ordenhar mais de 9 vacas por dia, além de não permitir que estes adquiram tecnologias para expandir a produção, como a ordenha mecanizada, por motivo de sua renda ser restringida.

Os valores para qualidade de vida são considerados altos comparando com estudo semelhantes no Sul do Brasil (GAMBIN et al., 2015), em que a média geral para qualidade de vida estabilizou em escore de 62,5 e também com produtores da região norte (MOURA; REMPEL; KOETZ, 2019) cuja qualidade de vida média é de 56,95. O estudo com produtores do sul (GAMBIN et al., 2015), apesar de ser realizado com produtores com idades compreendendo 60 e 69 anos, apresentou médias de 64,3 para o DF, 66,7 para o DP, 75,0 para o DS e 65,6 para o DA. Considerando os valores obtidos antes da ginástica laboral neste estudo, os escores obtidos são, em média, 7,3\% mais altos para DF, DP e DS e 9,3\% mais baixo para o DA ao comparar os resultados.

Das avaliaçóes posturais iniciais de produtores de leite, um estudo de Carvalho et al. (2015) detectou as principais modificações negativas na coluna vertebral, nos membros tanto superiores quanto inferiores, deteç̧áo de dor em diversos segmentos do corpo e baixa flexibilidade dos entrevistados, resultado este também alcançado por este estudo, porém, com a maior incidência de desconforto na região lombar e membros superiores. No mesmo estudo, após a prática de cinesioterapia laboral todos os dias da pesquisa, houve um aumento da flexibilidade do tronco, membros, e alívio das dores que antes eram constantes. É possível constatar que há uma associação dos desconfortos musculares com a atividade motora específica para a atividade leiteira, sendo que após a correção das más posturas, uma melhora pode ser sentida pelos envolvidos a curto e médio prazo.

\section{Consideraçóes Finais}

Com o estudo foi possível notar que o produtor rural que realiza a ordenha de forma manual possui uma carga horária semanal muito intensa, o que acarreta na sobrecarga de peso, repetiçấo de esforços, má postura, o que aumenta o risco de acidentes físicos, mecânicos e ergonômicos pela musculatura enfraquecida, além da sobrecarga psicológica de sua multifuncionalidade, aumentando o risco de acidentes químicos e biológicos. O motivo deste desgaste está na forma como necessita ser trabalhada a ordenha, feita todos os dias, sem dias de descanso, impedindo que o organismo, principalmente o sistema musculoesquelético, possa se recuperar por inteiro para iniciar a tarefa novamente.

A técnica de ginástica laboral apresentou uma melhora nos índices de qualidade de vida de produtores de leite que realizam ordenha manual na Comunidade Sáo Justino. Sua implantação de forma sistematizada promoveu benefícios aos participantes, conceituando a saúde não somente com a ausência de doenças, mas sim promovendo o bem-estar físico e mental como um todo. Sendo assim, é de se constatar que a ginástica laboral pode ser considerada mais um instrumento para promover a saúde, além de proporcionar maior vitalidade aos praticantes, mesmo iniciando em idades mais avançadas.

O número pequeno de entrevistados não permite generalizaçôes, sendo considerado até como limitante, mas incentiva a aplicação desta análise em outras comunidades com número maior de ordenhadores para dar veracidade aos dados e informaçôes obtidas. 
Assim, será possível legitimar que a sistemática da ginástica laboral possa influenciar de forma positiva na expansão da qualidade de vida para ordenhadores manuais.

\section{Referências}

ABESO - Associação Brasileira para o Estudo da Obesidade e da Síndrome Metabólica (Abeso). Diretrizes brasileiras de obesidade. 4. ed. São Paulo: Abeso; 2016.

\section{ACHOUR JÚNIOR, A. Bases para exercícios de alongamento relacionado com a} saúde e no desempenho atlético. 2.ed. Londrina: Phorte, 1999.

BARDIN, Laurence. Análise de conteúdo. São Paulo: Edições 70, 2012.

BORSANELLI, A. C.; SAMARA, S.I.; FERRAUDO, A. S.; DUTRA, I. S. Escolaridade e volume de produção têm associação com a percepção do risco de produtores de leite no uso de produtos veterinários. Pesq Vet Bras., v. 34, n. 10, p. 981-989, 2014.

BRASIL. Lei no 11.326, de 24 de julho de 2006. Estabelece as diretrizes para a formulação da Política Nacional da Agricultura Familiar e Empreendimentos Familiares Rurais, Pub. L. No. 11.326 (24 de Julho, 2006).

BRIZOLA, M. V.; GUIMARÁES, M. C. O perfil dos produtores de leite patronais e familiares do Distrito Federal. Informe Gepec, v. 18, n. 2, p. 6-19, 2014.

CARVALHO, T. G. M. L.; ROSA, V. M.; FACCO, A.; SILVA, P. R.; CAZAROTTO, D.; SILVA, L.; DOMENECH, S. C.; BORGES Jr., N. G. Produtor rural na atividade leiteira: uma experiência coletiva de educação em saúde. Cadernos de Educação Saúde e Fisioterapia, v. 2, n. 4, p. 85-93, 2015.

CAVALHEIRO, C. N.; REMPEL, C.; LAROQUE, L. F. S.; MACHADO, B. N. B. Perfil socioeconômico e análise da qualidade de vida dos produtores de leite da Comunidade São Justino, em Juína/MT. Destaques Acadêmicos, v. 6, n. 3, p. 148-156, 2014.

DAUGEARD, M. Mudanças e adaptações na agricultura familiar, estudo de caso em comunidades rurais de Juína, Mato Grosso. Confins - Revue Franco-Brésilienne de Géographe, n. 33, on line. 2017. DOI: 10.4000/confins.12516

EMBRAPA - Empresa Brasileira de Pesquisa Agropecuária (EMBRAPA). Manual de manutençáo da qualidade do leite cru refrigerado armazenado em tanques coletivos para produtores, técnicos, transportadores e coletadores de amostras de leite. Minas Gerais (MG): Embrapa Gado de Leite - Documentos; 2018. 25 p.

FAMATO - Federação da Agricultura e Pecuária do Estado de Mato Grosso (Famato), Serviço Nacional de Aprendizagem Rural no Estado de Mato Grosso (Senar-MT), Serviço Nacional de Aprendizagem em Cooperativismo no Estado de Mato Grosso 
(Sescoop-MT). Diagnóstico da cadeia produtiva do leite no Estado de Mato Grosso: relatório de pesquisa. Cuiabá (MT): Famato; 2011. 93 p.

GAMBIN, G.; MOLZAHN, A.; FUHRMANN, A. C.; MORAIS, E. P.; PASKULIN, L. M. G. Quality of life of older adults in rural southern Brazil. Rural Remote Health, v. 15, n. 3. Epub 3300, 2015.

INCRA - Instituto Nacional de Colonização e Reforma Agrária (INCRA). Tabela com módulos fiscais dos municípios. Brasil: Sistema Nacional de Cadastro Rural, 2013. 149 p.

LIMA, H. C. O.; AGUIAR, J. B; PAREDES, P. F. M.; GURGEL, L. A. Avaliação dos benefícios da ginástica localizada sobre a postura a flexibilidade de mulheres na terceira idade. Revista Brasileira de Educação Física e Esporte. São Paulo, v. 24, n. 4, p. 525534, 2010.

LIMA, V. Ginástica Laboral: atividade física no ambiente de trabalho. São Paulo: Phorte, 2003.

MACIEL, Á. C. C.; FERNANDES, M. B.; MEDEIROS, L. S. Prevalência e fatores associados à sintomatologia dolorosa entre profissionais da indústria têxtil. Rev. bras. epidemiol., São Paulo , v. 9, n. 1, p. 94-102, 2006.

MARTINS, C. O. Ginástica laboral no escritório. 2. ed. Jundiaí: Fontoura; 2001.

MENEZES, I. R.; ALMEIDA, A. C.; PINTO, M. S.; VELASCO, F. O.; MAIA, F. P.; RODRIGUES, G. V. Caracterização de unidades agrícolas familiares produtoras de leite no Norte do Estado de Minas Gerais. Rev Inst Laticínios Cândido Tostes, v. 69, n. 3, p. 153-163, 2014.

MOURA, W. N.; REMPEL, C.; KOETZ, L. C. E. Qualidade e estilo de vida de produtores de leite em propriedades rurais de um município do Cone Sul de Rondônia. Cadernos UniFOA, Volta Redonda, n. 40, p. 127-137, agosto 2019.

OLIVEIRA, C. C.; MORO, A. R. P.; ULBRICHT, L. Ergonomia aplicada à organização do trabalho da pecuária leiteira em pequenas propriedades no Paraná. Revista Perspectivas Contemporâneas, v. 12, n. 3, p. 193-214, 2017.

PADRÃO, M. B.; SENS, Y. A. S. Quality of life of living kidney donors in Brazil: an evaluation by the short form-36 and the WHOQOL-bref questionnaires. Clinical Transplantation, Nova Jersey, v. 23, n. 5, p. 621-627, 2009

PICOLI, T.; ZANI, J. L.; PETER, C. M.; LATOSINSKI, G. S.; FISCHER, G. Nível de instrução de produtores rurais e as características da produçáo leiteira. Science and animal Health, v. 2, n. 2, p. 147-159, 2014. 
SANTOS, A. F.; ODA, J. Y.; NUNES, A. P. M.; GONÇALVES, L.; GÁRNES, F. L. S. Benefícios da ginástica laboral na prevenção dos distúrbios osteomusculares relacionados ao trabalho. Ar Ciênc Saúde Unipar, v. 11, n. 2, p. 107-113, 2007.

SCOPEL, E.; ALENCAR, M.; CRUZ, R.M. Medidas de avaliação da dor. Revista Digital, Buenos Aires - Ano 11, n. 105, 2007.

SOUSA, F. F.; SILVA, J. A. A métrica da dor (dormetria): problemas teóricos e metodológicos. Revista DOR, v.6, p.469-513, 2005.

THE WHOQOL GROUP. The World Health Organization quality of life assessment (WHOQOL): position paper from the World Health Organization. Soc Sci Med, v. 41, n. 10, p. 1403-1409, 1995.

WELLS, K. F.; DILLON, E. K. The site and reach: a test of back and leg flexibility. Research Quarterly for Exercise and Sport, Washington, v. 23, p. 115-118, 1952.

WINCK, C. A.; THALER NETO, A. Perfil de propriedades leiteiras de Santa Catarina em relação à Instrução Normativa 51. Rev Bras Saúde Prod Anim, v. 13, n. 2, p. 296305, 2012. 